\title{
CARACTERIZAÇÃO MINERALÓGICA DE MINÉRIOS DE FERRO ITABIRÍTICOS PRINCIPALMENTE POR MINERAL LIBERATION ANALYSER (MLA)*
}

\section{Resumo}

Ana Cláudia Carioca ${ }^{1}$
Paulo Roberto Gomes Brandãoª

Devido à complexidade dos minérios itabiríticos, sua caracterização é necessária, com ênfase em microestrutura. Muito usado é o microscópio eletrônico de varredura (MEV), com microanalisador químico por dispersão de energia (EDS). Métodos computadorizados/automatizados de análise mineralógica e microestrutural, incluindo a liberação dos minerais, têm sido propostos, usando MEV-EDS. Um desses sistemas analíticos é o MLA (Mineral Liberation Analyser), que usa análise de imagens de elétrons retroespalhados (BSE) e espectros de raios-X (EDS) na identificação dos minerais, em secções polidas de partículas de minérios. Assim, geram-se mapas de composição microestrutural, com informações importantíssimas como liberação, associações minerais e análises modais. Há grande significado estatístico, pois vários milhares de partículas podem ser analisadas. Estudaram-se 4 amostras de minérios de ferro do Quadrilátero Ferrífero, MG, com graus diferentes de complexidade microestrutural. As faixas granulométricas $(-0,500+0,300 \mathrm{~mm}$ e $-0,300+0,212 \mathrm{~mm})$ foram estudadas por difração de raios-X, espectrometria Mössbauer e MLA. Pelos métodos instrumentais, os minerais abundantes foram quartzo e hematita, obviamente; também foram identificados goethita, gibbsita e magnetita, minoritários; em geral, os dados do MLA foram consistentes com esses. O quartzo se encontra liberado em 3 amostras, acima de $90 \%$; a exceção é a amostra APV4 com liberação de $60 \%$, onde o quartzo está associado a hematita (principalmente) e goethita.

Palavras-chave: Caracterização; Minério de ferro; MLA; Liberação

\section{MINERALOGICAL CHARACTERIZATION OF ITABIRITIC IRON ORES MAINLY BY MINERAL LIBERATION ANALYSER (MLA)}

\begin{abstract}
Due to the complexity of itabirite ores, their characterization is required, with emphasis on microstructure. Widely used is the scanning electron microscope (SEM) with the chemical energy-dispersive microanalyzer (EDS). Computerized/automated methods of mineralogical and microstructural analysis, including minerals liberation, have been proposed, using SEMEDS. One of these analytical systems is the MLA (Mineral Liberation Analyzer) which uses backscattered electrons images (BSE) and X-ray spectra (EDS) to identify the minerals in polished sections of ore particles. Thus, microstructural composition maps are generated, with very important information such as liberation, mineral associations and modal analysis. There is excellent statistical significance because several thousand particles can be analyzed. Four samples of iron ores from Iron Quadrangle, Minas Gerais, with different degrees of microstructural complexity have been studied. The particle sizes $(-0.500$ $+0.300 \mathrm{~mm}$ and $-0.300+0.212 \mathrm{~mm}$ ) were analyzed by X-ray diffraction, Mössbauer spectroscopy and MLA. By the instrumental methods, abundant minerals were quartz and hematite, obviously; also identified were goethite, and the minor gibbsite and magnetite. In general, these data were consistent with MLA's. Quartz liberation was above $90 \%$ in three samples; the exception is APV4 sample with only $60 \%$ quartz liberation, where quartz is associated with hematite (mainly) and goethite.
\end{abstract}

Keywords: Characterization; Iron ore; MLA; Liberation.

1 Formada em Química (UFOP); Doutora em Tecnologia Mineral (UFMG); Professora da Faculdade Adjetivo CETEP, Mariana, MG, Brasil.

2 Formado em Engenharia de Minas; PhD (UBC, Vancouver, Canadá); Professor Emérito, Universidade Federal de Minas Gerais - Departamento de Engenharia de Minas, Belo Horizonte, MG, Brasil.

* Contribuição técnica ao $44^{\circ}$ Seminário de Redução de Minério de Ferro e Matérias-primas, 15은 Simpósio Brasileiro de Minério de Ferro e 2o Simpósio Brasileiro de Aglomeração de Minério de Ferro, 15 a 18 de setembro de 2014, Belo Horizonte, MG, Brasil. 


\section{INTRODUÇÃO}

O aumento na demanda de produtos provenientes de minério de ferro fez deste um bem mineral importante para a economia mundial e do seu processo de caracterização, uma área de pesquisa que vem incorporando muitos avanços para que se obtenha uma melhor rota de processamento e, por fim, um concentrado com teores de impurezas cada vez menores.

A grande variedade de microestruturas e de tramas encontradas nos minérios de ferro tipo itabirito do Quadrilátero Ferrífero gera uma ampla diversidade de propriedades físicas com grandes implicações para o seu beneficiamento. O vínculo entre geologia do depósito, mecanismos de deformação que atuaram na formação das microestruturas e tramas ou orientações cristalográficas preferenciais, fornece resultados que podem ser aplicados para uma explotação estratégica dos diferentes tipos de minérios, implicando na melhoria de áreas alvos [1].

A caracterização mineralógica é um método no qual são necessárias a utilização e a integração de vários equipamentos para a obtenção de resultados satisfatórios sobre os minerais estudados. Isto é especialmente válido para os minérios de ferro complexos, devido à grande variabilidade que eles apresentam, podendo assim auxiliar na melhor escolha da rota de beneficiamento pela qual irá passar o minério. A caracterização bem realizada permite entender o possível comportamento dos minerais frente às etapas de processamento, bem como prever problemas prováveis ou dificuldades encontradas durante o processo [2-4].

Quando se trata de caracterização mineral, um dos pontos importantes é o estudo do grau de liberação do mineral de interesse em relação aos minerais de ganga. Esses dados são parâmetros fundamentais utilizados para a concepção da planta e processo de concentração do minério. Em reconhecimento a isso, diversos sistemas de medição vêm sendo desenvolvidos, principalmente tendo como base a técnica do microscópio eletrônico de varredura (MEV) para estudo de seções polidas de amostras de partículas, usualmente em frações granulométricas definidas [5-10].

A técnica de microscopia digital vem ganhando espaço, por exemplo, na microscopia óptica e no MEV (microscopia eletrônica de varredura), por se tratar de técnica que utiliza instrumentos controlados por software e que permite realizar varreduras completas nas amostras. Um exemplo de software de aquisição e análises de imagens é o MLA (Mineral Liberation Analyzer). Esse sistema de caracterização microestrutural é acoplado ao MEV com EDS e permite o estudo bem completo e detalhado das amostras, fornecendo informações importantes e específicas, como grau de liberação, composição química, associações mineralógicas, identificação e quantificação dos minerais, em uma análise relativamente rápida e eficaz [11].

Assim, o Mineral Liberation Analyser (MLA) é um sistema de medição automatizado nas pesquisas minerais. Foi desenvolvido pelo Dr. Ying Gu do JKTech ou Julius Kruttschnitt Mineral Research Centre (JKMRC), anexo à Universidade de Queensland-Austrália, em 1997 [12]. Na época, representou um método eficiente de combinar a análise de imagens de elétrons retroespalhados (BSE) e de espectros de raios $X$ (EDS) na identificação do mineral para a caracterização quantitativa de liberação mineral. Atualmente, o sistema analítico MLA é produzido e vendido pela FEI Company.

A análise é bem simples, porém tem que se tomar alguns cuidados em relação à aquisição das imagens BSE, pois algumas partículas se apresentam aglomeradas ou em contato com outras, o que pode levar à obtenção de resultados tendenciosos para a liberação. Então, são realizadas correções, como a desaglomeração

\footnotetext{
* Contribuição técnica ao $44^{\circ}$ Seminário de Redução de Minério de Ferro e Matérias-primas, 15은 Simpósio Brasileiro de Minério de Ferro e $2^{\circ}$ Simpósio Brasileiro de Aglomeração de Minério de Ferro, 15 a 18 de setembro de 2014, Belo Horizonte, MG, Brasil.
} 
(separação). A parte mais importante é a segmentação (identificar todas as fases minerais distintas (ou grãos)) pelos diferentes tons de cinzas e composições químicas pelo EDS.

O objetivo do trabalho foi analisar e comparar resultados obtidos em várias técnicas de caracterização: difração de raios- $X$, espectroscopia Mössbauer, análise química e MLA, dando mais ênfase a este último, para 4 amostras de minério de ferro com graus diferentes de complexidade microestrutural.

\section{MATERIAIS E MÉTODOS}

\subsection{Amostras Estudadas}

Estudaram-se 4 amostras de minérios de ferro do Quadrilátero Ferrífero, MG, com graus diferentes de complexidade microestrutural. As faixas granulométricas escolhidas foram $-0,500+0,300 \mathrm{~mm}$ e $-0,300+0,212 \mathrm{~mm}$, por serem estas as malhas de liberação para quase todas as amostras pesquisadas.

\subsection{Análises Químicas}

Foi usada análise via úmida (dicromatometria) para a determinação do Fe total e espectrômetro de emissão atômica a plasma (ICP) modelo Cirus CCD da Spectro Instruments, para a determinação de $\mathrm{Al}_{2} \mathrm{O}_{3}, \mathrm{MnO}_{2}, \mathrm{P}$. A $\mathrm{SiO}_{2}$ foi calculada por diferença. As análises foram realizadas pelas empresas Samarco e Vale.

\subsection{Difração de Raios X - DRX}

Os difratogramas foram coletados em um difratômetro Shimadzu, modelo XRD 6000, equipado com tubo de $\mathrm{Fe}$, com comprimento de onda $(\lambda)$ igual a $1,937 \AA$, e monocromador de grafita. As varreduras foram feitas entre 7-70 (2-theta) com velocidade do goniômetro de $2^{\circ}$ por minuto. Foi utilizado o software JADE para a identificação das fases nas amostras. A análise foi realizada no Laboratório de Difração de Raios X do Departamento de Química da Universidade Federal de Ouro Preto (UFOP).

\subsection{Espectroscopia Mössbauer - EMO}

Os espectros foram coletados à temperatura ambiente (RT) com um espectrômetro operando no modo de aceleração constante e a acumulação dos dados foi feita com um analisador multicanal com 512 e/ou 1024 canais e intervalo de velocidade -11 a $+11 \mathrm{~mm} / \mathrm{s}$. Os absorvedores foram preparados misturando-se cerca de 30 a $40 \mathrm{mg}$ da amostra com glicose, a fim de se obter cerca de 10 a 20 mg de Fe por centímetro quadrado. Os ajustes foram realizados computacionalmente com sextetos e/ou dubletos simétricos ou com um modelo independente de distribuição do campo hiperfino. Os desvios isoméricos são dados em referência ao ferro metálico ( $\alpha-\mathrm{Fe}$ ) $[13,14]$. A partir dos sextetos e dubletos obtidos foram determinadas as áreas relativas de cada componente mineral contendo ferro em sua estrutura. Esta análise foi realizada no Laboratório de Espectroscopia Mössbauer do Departamento de Química da UFOP.

\footnotetext{
* Contribuição técnica ao $44^{\circ}$ Seminário de Redução de Minério de Ferro e Matérias-primas, $15^{\circ}$ Simpósio Brasileiro de Minério de Ferro e $2^{\circ}$ Simpósio Brasileiro de Aglomeração de Minério de Ferro, 15 a 18 de setembro de 2014, Belo Horizonte, MG, Brasil.
} 


\subsection{Mineral Liberation Analyzer - MLA}

Foram preparadas secções polidas (pastilhas) das amostras das faixas granulométricas retidas em $0,300 \mathrm{~mm}$ e $0,212 \mathrm{~mm}$. As amostras foram impregnadas em resina epóxi e endurecidas; em seguida, foi realizado o polimento e, posteriormente, o recobrimento por película de carbono.

As aquisições dos dados foram feitas no equipamento MLA 650F System, MEV-FEG FEI Quanta 650F, espectrômetro Bruker Quantax com software Esprit, do Centro de Microscopia da Universidade Federal de Minas Gerais (UFMG).

Todas as análises realizadas pelo MLA foram feitas em condições comparativas para os modos de aquisição de dados XBSE e GXMAP, que se distinguem pelos critérios de medição e o tempo de análise. O XBSE tem seu fundamento na obtenção de um único espectro de raios $X$ (EDS) para cada região de tom de cinza diferente (ou grão/fase) das imagens BSE da amostra; o tempo de coleta é 33 milissegundos para cada análise química. Já para o GXMAP, além da coleta de um espectro de raios $X$ para cada área de tom de cinza, uma fase definida por um intervalo de tom de cinza é selecionada para que seja mapeada em detalhe, ou seja, nestes grãos muitos espectros EDS são coletados, segundo uma malha prédefinida. Evidentemente, para a mesma amostra, a análise por GXMAP é bem mais demorada, mas a confiabilidade na fase detalhada é muito melhor do que no modo XBSE.

A liberação é um aspecto muito relevante na área de tecnologia mineral, pois é impactante no estudo das rotas de concentração mineral. O sistema MLA calcula a liberação de duas maneiras: a) a liberação por composição, onde se leva em conta a composição mineralógica mássica da partícula e não se o mineral de interesse está livre na borda da partícula; b) a liberação por superfície livre, que só leva em conta as áreas de cada grão mineral expostas na superfície da partícula.

A análise modal é o resultado da determinação da porcentagem da área (\% area) ocupada por um determinado mineral nas secções polidas analisadas. A partir daí, pode-se calcular as porcentagens em volume e em massa (\%M) de cada um dos minerais componentes da amostra. $\mathrm{Na}$ abordagem pelo MLA, esta composição de fases pode ser determinada tanto por XBSE como GXMAP.

Os parâmetros estabelecidos para o trabalho estão relatados na tabela 1.

Tabela 1. Dados de aquisição para análise no MLA

\begin{tabular}{lclc}
\hline Contraste & $30^{*}$ & Aumento & $100 \times$ e $75 x$ \\
\hline Brilho & $80^{*}$ & Frames & 277 e 145 \\
\hline Spot Size & 5,5 & № de partículas & 20000 \\
\hline Voltagem & $25 \mathrm{KV}$ & Tempo & 360 minutos \\
\hline Distância de Trabalho & 12 & Tamanho mínimo & 100 pixels \\
\hline GXMAP (Goethita) & $101-150^{* *}$ & Resina & $0-20^{* *}$ \\
\hline Pontos de Raios X & 33 milissegundos & Speed & 16 \\
\hline${ }^{*}$ Padrão de Cobre & ${ }^{* *}$ Tom de cinza & &
\end{tabular}

\section{RESULTADOS E DISCUSSÃO}

A análise química quantitativa (Tabela 2) das amostras não apresentou resultados discrepantes em relação aos componentes mais importantes e rotineiros $\left(\mathrm{Fe}_{\mathrm{T}}, \mathrm{SiO}_{2}\right.$, $\mathrm{Al}_{2} \mathrm{O}_{3}, \mathrm{P}, \mathrm{MnO}_{2}$ e PPC) analisados em se tratando de minério de ferro.

A amostra APV3 destaca-se por ter um teor de $\mathrm{Al}_{2} \mathrm{O}_{3}$ em torno de $3 \%$; este teor elevado é indicativo da presença de minerais contendo alumínio, como os

* Contribuição técnica ao $44^{\circ}$ Seminário de Redução de Minério de Ferro e Matérias-primas, 15ㅇ Simpósio Brasileiro de Minério de Ferro e 2o Simpósio Brasileiro de Aglomeração de Minério de Ferro, 15 a 18 de setembro de 2014, Belo Horizonte, MG, Brasil. 
argilominerais, caulinita $\left(\mathrm{Al}_{2} \mathrm{Si}_{2} \mathrm{O}_{5}(\mathrm{OH})_{4}\right)$ e/ou gibbsita $\left(\mathrm{Al}(\mathrm{OH})_{3}\right)$. A mesma amostra também apresentou o maior valor de $P$ alcançando $0,082 \%$. Valores elevados de $P$ são uma característica de minérios goethíticos. Outra característica de itabiritos goethíticos é o valor elevado de PPC, o que foi observado nas amostras APS2 $(3,4 \%)$ e APV3 (5\%).

Tabela 2. Resultados das análises químicas quantitativas das amostras

\begin{tabular}{cccccccc}
\hline \multicolumn{7}{c}{ ANÁLISES QUÍMICAS } \\
\hline № & Amostra & $\mathrm{Fe}_{\mathrm{T}}$ & $\mathrm{SiO}_{2}$ & $\mathrm{Al}_{2} \mathrm{O}_{3}$ & $\mathrm{P}$ & $\mathrm{MnO}_{2}$ & $\mathrm{PPC}$ \\
\hline 1 & APS1 $+0,300$ & 42,71 & 36,84 & 0,3 & 0,036 & 0,06 & 1,66 \\
\hline 2 & APS1 $+0,212$ & 29,88 & 55,81 & 0,21 & 0,024 & 0,04 & 1,17 \\
\hline 3 & APS2 $+0,300$ & 42,52 & 35,11 & 0,47 & 0,065 & 0,07 & 3,41 \\
\hline 4 & APS2 $+0,212$ & 35,05 & 47,39 & 0,15 & 0,021 & 0,03 & 2,27 \\
\hline 5 & APV3 $+0,300$ & 59,41 & 6,83 & 3,28 & 0,082 & 0,105 & 4,47 \\
\hline 6 & APV3 +0,212 & 36,48 & 41,91 & 1,99 & 0,051 & 0,061 & 2,84 \\
\hline 7 & APV4 +0,300 & 40,92 & 39,27 & 0,68 & 0,028 & 0,032 & 0,65 \\
\hline 8 & APV4 $+0,212^{*}$ & 30,15 & 53,45 & 0,65 & 0,025 & 0,034 & --- \\
\hline
\end{tabular}

${ }^{*}$ Massa insuficiente para a determinação da PPC

\subsection{Difração de Raios X - DRX}

Em todas as amostras estudadas por DRX, o quartzo é abundante, seguido de hematita. Foi também identificado nas amostras APS1, APS2 e APV3, goethita na proporção de média-baixa, o que está coerente com a análise química, pois foram observados valores elevados para a PPC (perda por calcinação). Na amostra APV3 foi comprovada a existência de gibbsita entre os minerais principais, confirmando os resultados da análise química da amostra.

Os difratogramas da amostra APV3 estão mostrados na Figura 1, relação da amostra global em comparação com as faixas granulométricas escolhidas para análises no $\operatorname{MLA}(-0,500+0,300 \mathrm{~mm}$ e -0,300+0,212 mm).

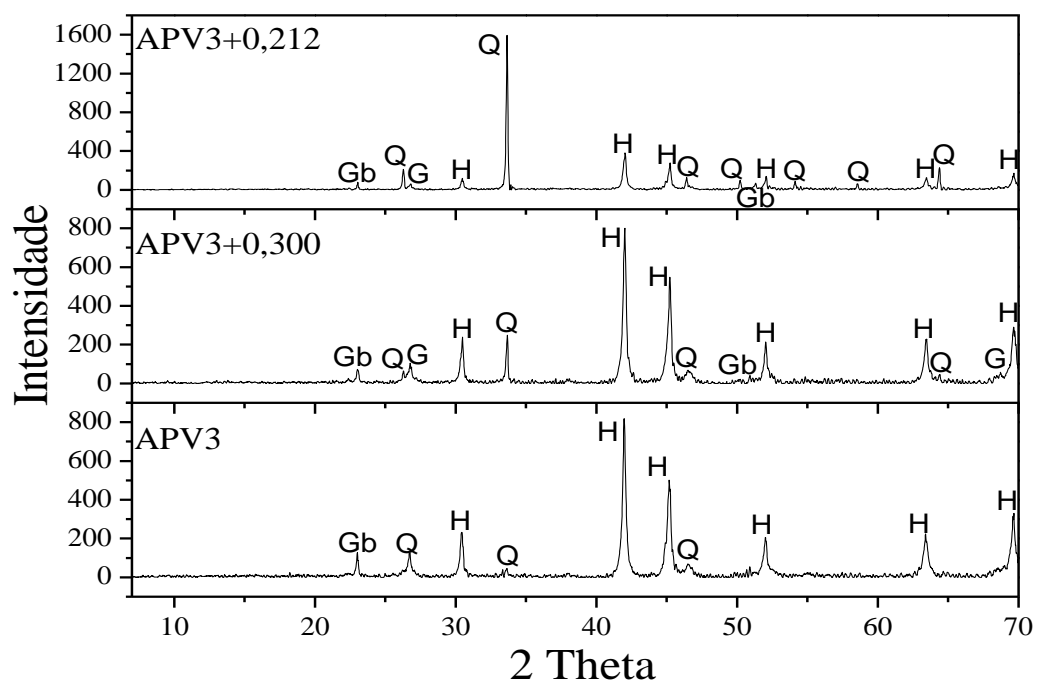

Figura 1. Difratograma da amostra APV3 utilizando o difratômetro com tubo de Fe. Hematita: $\mathrm{H}$; Goethita: G; Quartzo: Q; Gibbsita: Gb.

* Contribuição técnica ao 44 Seminário de Redução de Minério de Ferro e Matérias-primas, $15^{\circ}$ Simpósio Brasileiro de Minério de Ferro e $2^{\circ}$ Simpósio Brasileiro de Aglomeração de Minério de Ferro, 15 a 18 de setembro de 2014, Belo Horizonte, MG, Brasil. 
3.2 Espectroscopia Mössbauer - EMO

Em todas as amostras, bem como em todas as faixas granulométricas estudadas, a ocorrência dominante é da hematita, tendo sido observada goethita (sexteto e/ou dubletos) em quase todas as amostras e magnetita detectada como mineral minoritário somente na amostra APV3.

Como mostrado na Figura 2 é possível distinguir a coexistência de goethita (sexteto e dubleto) e magnetita (sextetos) além da hematita, para a amostra APV3, resultado este que vem corroborar com os obtidos pela difração de raios $X$. Nos espectros pode-se notar que o sexteto da hematita mostra-se bem simétrico, com valores bem definidos para o seu campo magnético, o que ressalta a existência de hematita bem cristalizada. Os espectros da amostra APV3 tanto para a goethita e a magnetita foram ajustados através de distribuição de campo hiperfino.

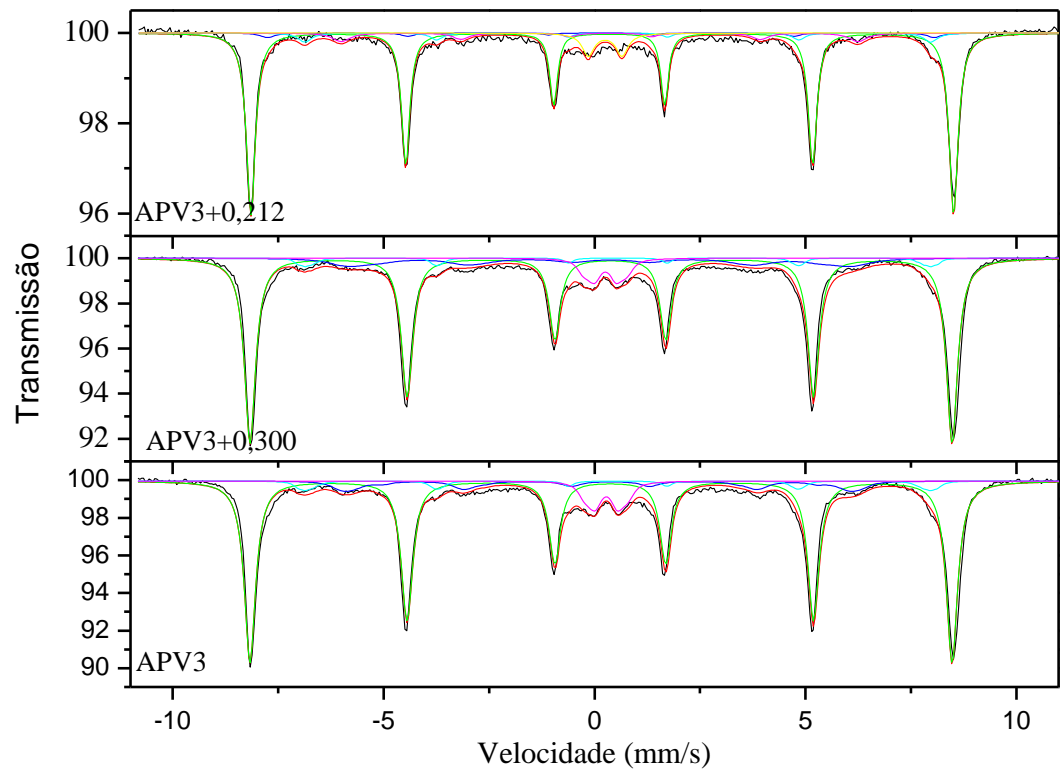

Figura 2. Espectro Mössbauer para a amostra APV3.

Através da análise espectral Mössbauer, e sabendo-se a análise química para a \% de ferro, pode-se calcular as quantidades relativas de todos os minerais portadores de ferro na amostra. Na Tabela 3, estão apresentados os valores obtidos para tal quantificação dos minerais hematita, goethita e magnetita para a amostra APV3; também mostram-se os minerais não portadores de ferro, cujas quantidades foram calculadas pela composição química.

Tabela 3. Composição quantitativa das amostras

\begin{tabular}{cccccc}
\hline Fração & $\begin{array}{c}\text { Hematita } \\
(\%)\end{array}$ & $\begin{array}{c}\text { Magnetita } \\
(\%)\end{array}$ & $\begin{array}{c}\text { Goethita } \\
(\%)\end{array}$ & $\begin{array}{c}\text { Quartzo } \\
(\%)\end{array}$ & $\begin{array}{c}\text { Gibbsita } \\
(\%)\end{array}$ \\
\hline$+0,300 \mathrm{~mm}$ & 65,7 & 3,4 & 17,5 & 8,4 & 5,0 \\
\hline$+0,212 \mathrm{~mm}$ & 40,5 & 4,5 & 7,8 & 44,2 & 3,0 \\
\hline$+0,150 \mathrm{~mm}$ & 35,2 & 3,8 & 6,9 & 51,9 & 2,2 \\
\hline
\end{tabular}

\footnotetext{
* Contribuição técnica ao $44^{\circ}$ Seminário de Redução de Minério de Ferro e Matérias-primas, $15^{\circ}$ Simpósio Brasileiro de Minério de Ferro e $2^{\circ}$ Simpósio Brasileiro de Aglomeração de Minério de Ferro, 15 a 18 de setembro de 2014, Belo Horizonte, MG, Brasil.
} 
3.3 MLA - MEV/EDS

A imagem processada (já segmentada) da amostra APV3 $+0,212 \mathrm{~mm}$ está mostrada na Figura 3.

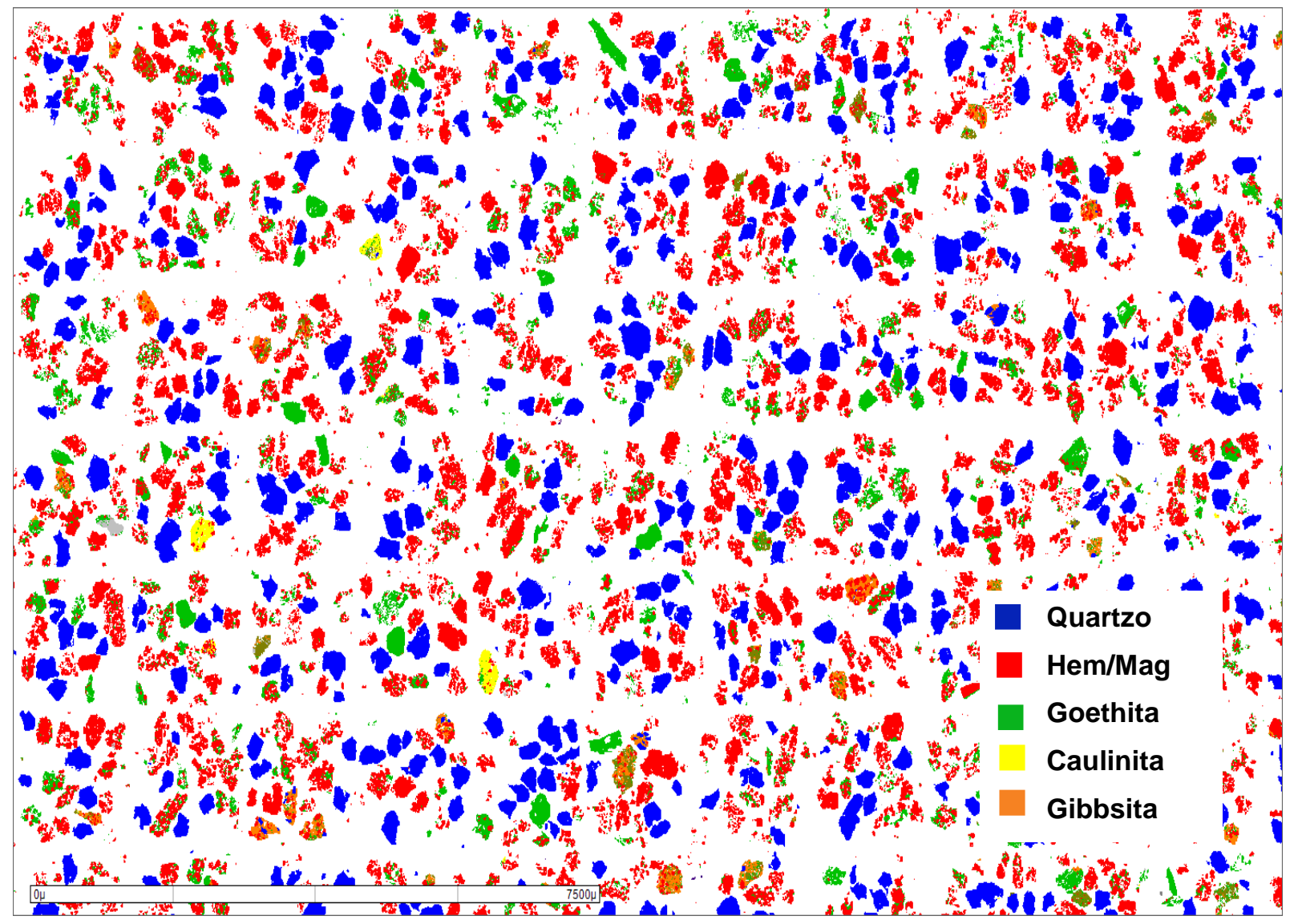

Figura 3. Imagem processada para a amostra APV3+0,212 mm.

Na Figura 4 apresenta-se uma partícula selecionada (mista), com a imagem BSE, os espectros de raios $\mathrm{X}$ e a imagem processada, mostrando os minerais detectados $\mathrm{e}$ mapeados.

* Contribuição técnica ao $44^{\circ}$ Seminário de Redução de Minério de Ferro e Matérias-primas, 15은 Simpósio Brasileiro de Minério de Ferro e 20 Simpósio Brasileiro de Aglomeração de Minério de Ferro, 15 a 18 de setembro de 2014, Belo Horizonte, MG, Brasil. 

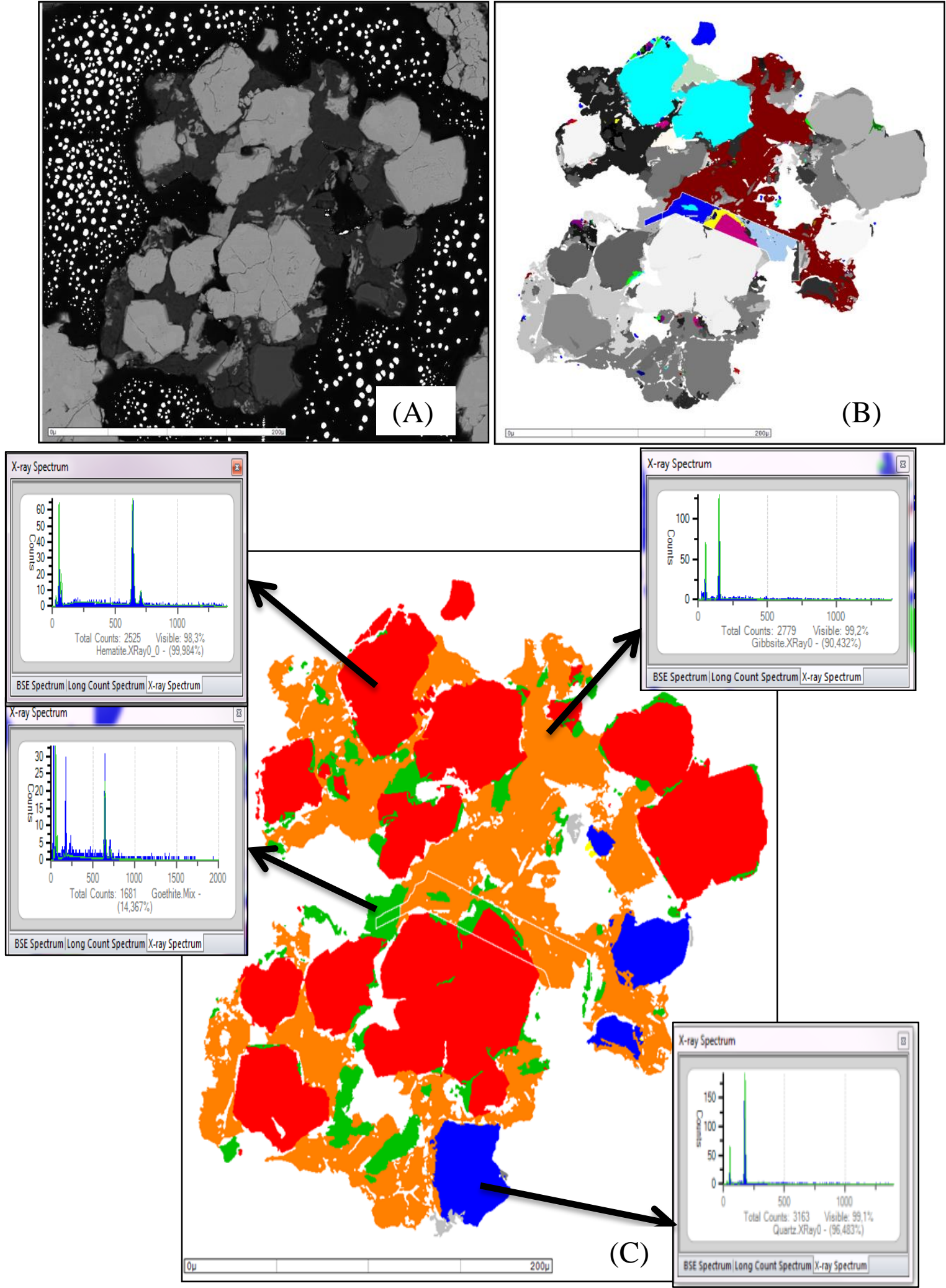

Figura 4. Imagem BSE (A), imagem de raios $X(B)$ e imagem processada $(C)$ para uma partícula da amostra APV3 +0,212 mm. Legenda: hematita (vermelho); quartzo (azul); gibbsita (laranja); goethita (verde).

* Contribuição técnica ao 44 Seminário de Redução de Minério de Ferro e Matérias-primas, 15은 Simpósio Brasileiro de Minério de Ferro e 20 Simpósio Brasileiro de Aglomeração de Minério de Ferro, 15 a 18 de setembro de 2014, Belo Horizonte, MG, Brasil. 


\subsubsection{Liberação por composição versus liberação por superfície}

O estudo da liberação foi realizado nos contextos de liberação por composição (LC) e liberação por superfície (LS).

$\mathrm{Na}$ APS1+0,212mm, o quartzo está praticamente livre considerando a superfície e a composição ( 90\%) e parcialmente livre na APS1+0,300mm em LS e LC ( 80\%). Em relação à APS2+0,300mm e APS2+0,212mm, este mineral está relativamente livre em torno de $70 \%$ e $85 \%$ respectivamente, tanto para LS e LC. O quartzo se encontra liberado nas amostras APV3+0,300mm e APV3+0,212mm, tanto na liberação por composição e na liberação por superfície livre.

A APV4 mostrou ter o menor valor de liberação para o quartzo. Na APV4+0,300mm praticamente todo o mineral está ligado-principalmente à hematita, com valor de LC e LS em torno de 10\%; já na APV4+0,212mm a liberação do quartzo é de aproximadamente $50 \%$, ou seja, em metade das partículas o quartzo encontra-se livre e na outra metade associado a outro mineral (hematita e/ou goethita).

No estudo de liberação, o sistema MLA leva em conta o número de partículas analisadas; no caso, esse critério depende do número de quadros (frames) analisados. Notou-se durante o processo de análise que estes números são diferentes para XBSE e GXMAP. Assim, mesmo tendo sido seguido o mesmo procedimento geral, o número de partículas analisadas foi superior a 4000 para GXMAP e maior que 5000 partículas para o XBSE. O número de partículas do XBSE é superior ao analisado por GXMAP, devido ao fato do modo GXMAP analisar por EDS muito mais detalhadamente (mapeamento) uma fase específica, no caso a goethita; isto demandou tempo mais longo na aquisição, assim analisando um número menor de partículas.

\subsubsection{Análise modal}

O resultado para a análise modal está detalhado na Tabela 3. Em todas as amostras e nas faixas estudadas, foi notado que sua composição mineralógica é basicamente hematita e quartzo totalizando mais de $70 \%$ da amostra, o que já era esperado tratando-se de minério de ferro tipo itabirito. O terceiro mineral em abundância foi a goethita. Para a amostra APV3, além dos minerais listados encontrou-se também caulinita, mas em quantidade muito pequena.

Os resultados das análises modais por MLA confirmaram os dados obtidos nas outras análises (Tabela 4).

Tabela 4. Resultado para a análise modal para as amostras nas duas faixas granulométricas

\begin{tabular}{ccccccc}
\hline \multirow{2}{*}{ Amostra } & \multicolumn{2}{c}{ Quartzo } & \multicolumn{2}{c}{ Hematita } & \multicolumn{2}{c}{ Goethita } \\
\cline { 2 - 7 } & $\begin{array}{c}\text { XBSE } \\
(\%)\end{array}$ & $\begin{array}{c}\text { GXMAP } \\
(\%)\end{array}$ & $\begin{array}{c}\text { XBSE } \\
(\%)\end{array}$ & $\begin{array}{c}\text { GXMAP } \\
(\%)\end{array}$ & $\begin{array}{c}\text { XBSE } \\
(\%)\end{array}$ & $\begin{array}{c}\text { GXMAP } \\
(\%)\end{array}$ \\
\hline APS1 +300mm & 18,64 & 18.16 & 66,88 & 68,69 & 14,39 & 13,07 \\
\hline APS1 $+212 \mathrm{~mm}$ & 35,81 & 34,79 & 55,12 & 58,23 & 8,18 & 6,86 \\
\hline APS2 $+300 \mathrm{~mm}$ & 20,96 & 21,19 & 59,32 & 46,50 & 19,25 & 31,77 \\
\hline APS2 $+212 \mathrm{~mm}$ & 32,13 & 28,18 & 45,35 & 52,08 & 22,09 & 19,65 \\
\hline APV3 +300mm & 3,05 & 3,53 & 64,94 & 67,21 & 29,84 & 27,34 \\
\hline APV3 $+212 \mathrm{~mm}$ & 24,69 & 25,19 & 61,66 & 60,37 & 12,23 & 13,22 \\
\hline APV4 +300mm & 32,70 & 32,25 & 63,97 & 62,67 & 2,71 & 3,38 \\
\hline APV4 +212mm & 40,91 & 40,37 & 55,13 & 54,85 & 3,55 & 4,00 \\
\hline
\end{tabular}

* Contribuição técnica ao $44^{\circ}$ Seminário de Redução de Minério de Ferro e Matérias-primas, 15은 Simpósio Brasileiro de Minério de Ferro e $2^{\circ}$ Simpósio Brasileiro de Aglomeração de Minério de Ferro, 15 a 18 de setembro de 2014, Belo Horizonte, MG, Brasil. 
Resultados variados e valiosos podem ser extraídos da análise MLA, tais como análise modal, associação mineral, locking ou intercrescimento dos minerais, liberação mineral etc. As análises pelos critérios bem diferentes XBSE e GXMAP, forneceram resultados muito semelhantes.Isto foi importante, pois mostrou a consistência dos resultados.

A liberação é um aspecto muito relevante e sujeito a controvérsia na área de tecnologia mineral, pois este resultado é impactante no estudo das rotas de concentração mineral. Nas 4 amostras estudadas, não houve valores discrepantes se comparadas as técnicas de liberação por composição e área superficial e os critérios de aquisição de dados XBSE e GXMAP. Contudo, foi observado que a liberação por composição gerou valores um pouco maiores. As duas técnicas de liberação comprovaram que o quartzo está praticamente livre, mesmo para a fração mais grossa, retida em 0,300 mm, para 3 das amostras, exceção para APV4.

A principal dificuldade do MLA é a identificação de minerais com composições químicas muito próximas, como hematita e magnetita.

O sistema MLA é muito detalhado em suas análises, desde o processo de aquisição dos dados, como também no tratamento dos mesmos e mostra dos resultados. Uma grande vantagem da análise é o significado estatístico, pois milhares de partículas podem ser analisadas numa sequência, onde até 14 secções polidas podem ser medidas por batelada. A demora da análise, nestas condições, pode ser de várias horas.

\section{Agradecimentos}

Os autores agradecem a todos que colaboraram na realização deste trabalho, especialmente aos técnicos: Alberto, Isabel, Andréia, Roberto e Paola. A.C.Carioca agrade à CAPES / PROEX, pelo apoio acadêmico e financeiro. P.R.G. Brandão também agradece ao CNPq por uma bolsa e recursos de pesquisa.

\section{REFERÊNCIAS}

1 Selmi M, Lagoeiro LE, Endo I. Geochemistry of hematitite and itabirite, Quadrilátero Ferrífero, Brazil. REM: Revista Escola Minas, Ouro Preto, 2009; 62(1): 35-43.

2 Vianna SMSM. Caracterização de dois minérios de ferro itabiríticos do Quadrilátero Ferrífero-MG. Dissertação, Mestrado em Engenharia Metalúrgica e de Minas, Tecnologia Mineral. Escola de Engenharia da UFMG, 162p. Belo Horizonte. 1993.

3 Rocha JMP. Definição da tipologia e caracterização mineralógica e microestrutural dos itabiritos anfibolíticos das Minas de Alegria da Samarco Mineração S.A. - Minas Gerais Volume 1. Universidade Federal de Minas Gerais (UFMG). PPGEM. Tese de Doutorado. 460p. 2008.

4 Carioca AC. Caracterização de minério de ferro por espectroscopia de reflectância difusa. Dissertação de Mestrado. Programa de Pós-graduação em Engenharia Mineral. Universidade Federal de Ouro Preto. Ouro Preto-MG. 101p. 2010.

5 Jones MP. Applied mineralogy: a quantitative approach. London; Norwell, MA, Graham \& Trotman. 1987.

$6 \quad$ King RP, Schneider CL. An effective SEM-based image analysis system for quantitative mineralogy. Kona Journal 11. 1993.

7 Lastra R, Petruk W, Wilson J. Image analysis techniques and applications to mineral processing. In: Cabri LJ, Vaughan DJ. (Eds.), Modern Approaches to Ore and

* Contribuição técnica ao 44 Seminário de Redução de Minério de Ferro e Matérias-primas, $15^{\circ}$ Simpósio Brasileiro de Minério de Ferro e $2^{\circ}$ Simpósio Brasileiro de Aglomeração de Minério de Ferro, 15 a 18 de setembro de 2014, Belo Horizonte, MG, Brasil. 
Environmental Mineralogy. Mineral. Assoc. Can.,Short Course, vol.27, pp.327-366. 1998.

8 Petruk W. Applied mineralogy in the mining industry. Elsevier Science B.V., Amsterdam, 268p. 2000.

9 Petruk W. Imaging of minerals, ores and related products to determine mineral characteristics. Minerals and Metallurgical Processing, v. 19, n. 1, p. 50-56, Science BV. 2002.

10 Gu Y Automated Scanning Electron Microscope Based Mineral Liberation Analysis - An Introduction to JKMRC/FEI Mineral Liberation Analyser. Journal of Minerals and Materials Characterisation and Engineering, 2003; 2(1): 33-41.

11 Paciornik S, Maurício MHP. Digital Imaging. In: Vander-Voort, G. F. (Ed.). ASM Handbook, Volume 9: Metallography and Microstructures. Materials Park (OH, USA): ASM International, p. 368-402. 2004.

$12 \mathrm{Gu}$ Y, Napier-Munn T. JK/ Philips mineral liberation analyzer - an introduction. Minerals Processing '97 Conf. Cape Town,SA,p.2. 1997.

13 Fandrich R, Gu Y, Burrows D, Moeller K. Modern SEM-based mineral liberation analysis. International Journal of Mineral Processing, 84 310-320. 2007.

14 Bancroft GM. Mössbauer Spectroscopy: An Introduction for Inorganic Chemists and Geochemists, John Wiley \& Sons, New York, 1973.

* Contribuição técnica ao $44^{\circ}$ Seminário de Redução de Minério de Ferro e Matérias-primas, 15o Simpósio Brasileiro de Minério de Ferro e 2o Simpósio Brasileiro de Aglomeração de Minério de Ferro, 15 a 18 de setembro de 2014, Belo Horizonte, MG, Brasil. 